\title{
Skin Diseases in South Africa
}

JAMES MARSHALL, M.D., CAPE TOWN, SOUTH AFRICA

The main factors that influence the incidence of skin diseases in South Africa, as in Africa as a whole, are race, climate, nutrition, migration, way of life and occupation, and medication or lack of it.

\section{Race}

The chief racial groups ${ }^{\mathbf{1 , 2}}$ in South Africa are the Bantu $(11,000,000)$ who are Hamiticized Negroes, the whites $(3,000,000)$ who are mainly of Dutch, British, German, and French descent, the Indians $(500,000)$, and the colored people $(1,500,000)$ who are of mixed stock. The remnants of the Bushmen and Hottentots live in South-West Africa.

From the Department of Dermatology, University of Stellenbosch.

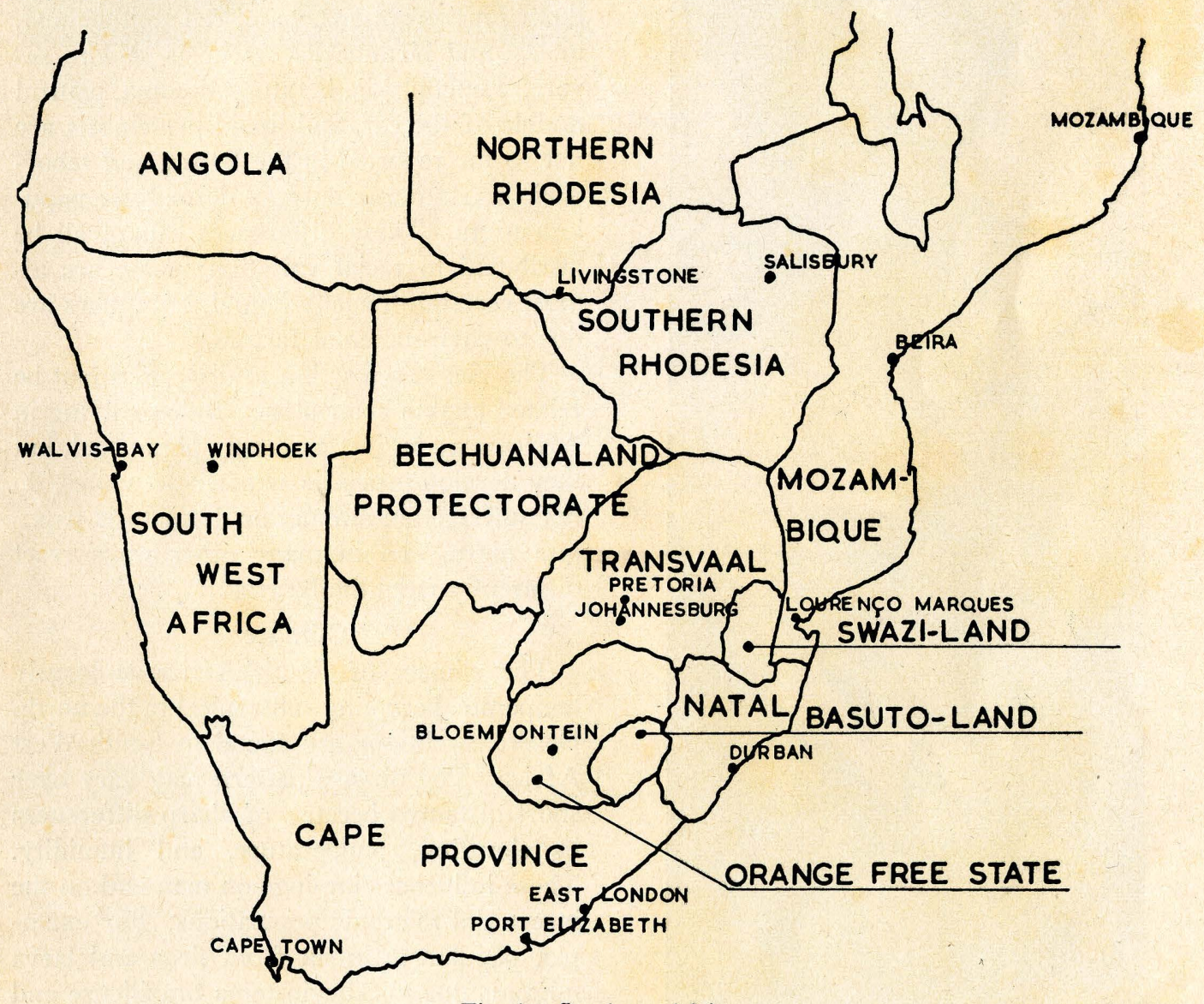

The white people suffer from most of the dermatoses encountered in Europe as well as develop all the photosensitivity diseases oftener and at an earlier age than do their counterparts in Europe. Inbreeding in the early days of white settlement has led to the propagation of some inheritable diseases of which familial hepatic porphyria is the most important.

Allowing for pigmentary variation, the colored people's reaction to skin disease resembles that of the white more than that of the Bantu.

The basic differences between the Negro and the white in regard to dermatoses need from diseases peculiar to Africa, and they 


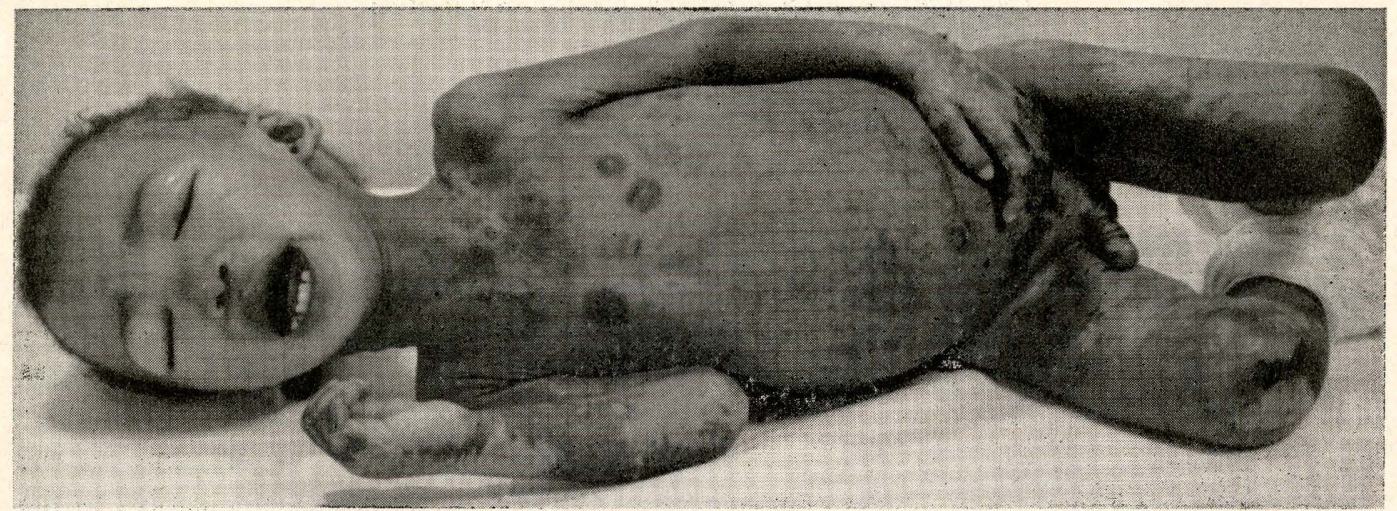

Fig. 2.-Kwashiorkor in a colored infant.

Fig. 3.-Pellagra is the commonest manifestation of malnutrition in the adult Bantu.

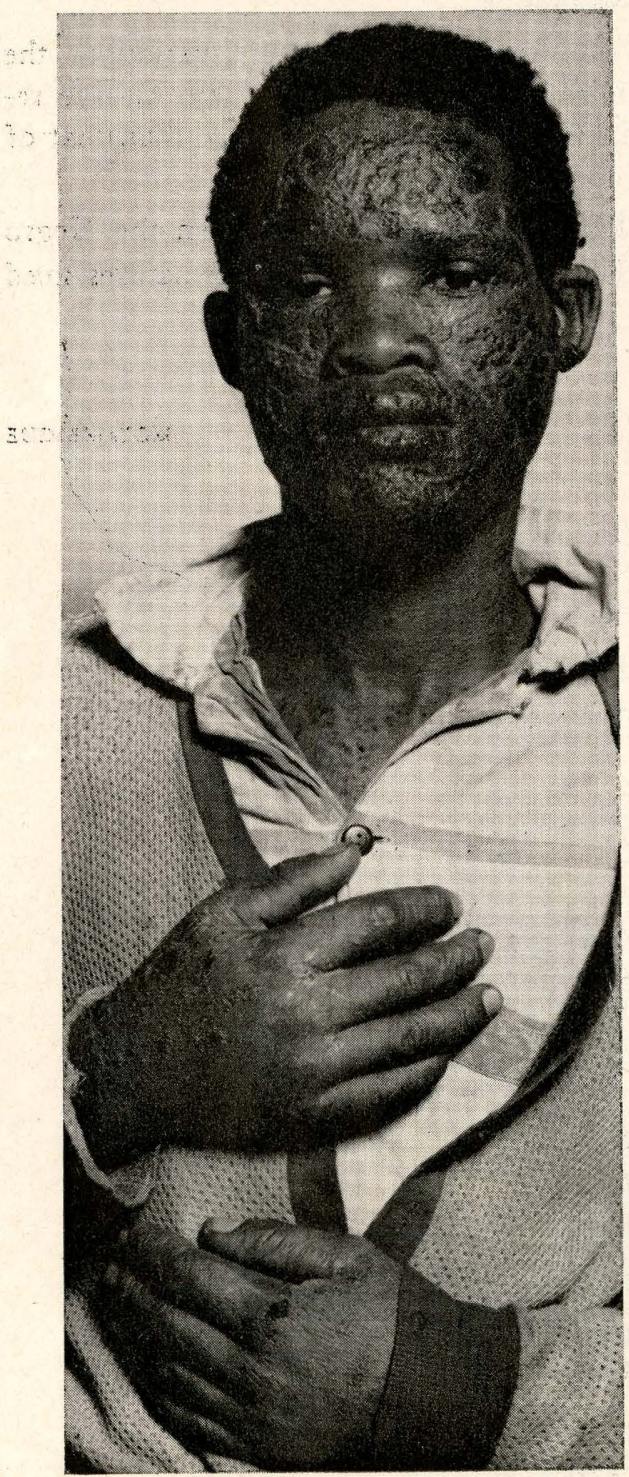

no detailed recapitulation here. The fibroplastic diathesis of the Negro is well known. True ainhum, dermatosis papulosa nigra, and onyalai are largely restricted to Negroes. Some diseases rarer in Negroes than in whites are solar dermatoses, psoriasis, the eczemas, prickly heat, dermatitis artefacta, pruritus ani et vulvae, the alopecias, xanthomatous eruptions, basal-cell epithelioma, moles, and birthmarks. Acne is seldom severe. Leukoplakia, keratoacanthoma, painful nodule of the ear, and lipoid proteinosis are not so far reported in the Bantu, and seborrheic warts occur only as dermatosis papulosa nigra. These differences cannot all be attributed to racial variation; some are almost certainly racially bound, but others are due to environmental factors.

The Negro's reaction to disease cannot be related to skin color alone. Indians living in Africa may be just as deeply pigmented, but they develop psoriasis as often as whites, do not suffer from ainhum or dermatosis papulosa nigra, and in many other ways react differently from the Negro.

\section{Climate}

The climate of South Africa is largely temperate, becoming subtropical in the north. Desert conditions are found in South-West Africa. The disease pattern may vary over short distances because of sharp differences in elevation, temperature, and humidity. These influences impinge on man and on the insect and microbic populations. For example, papular urticaria from fleas and larva migrans due to Ancylostoma braziliense and 


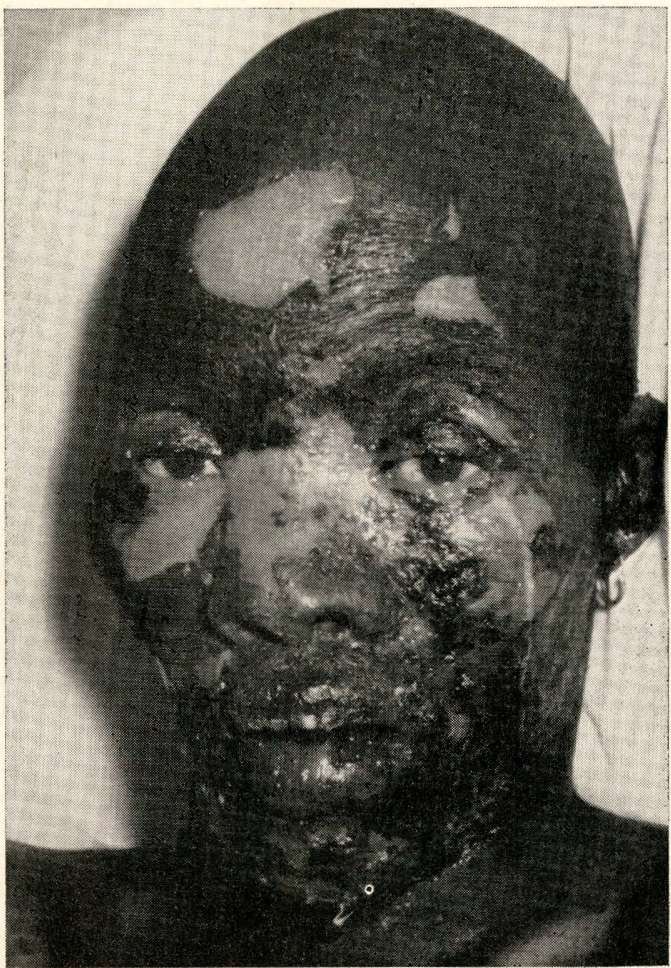

Fig. 4.-The Stevens-Johnson syndrome occurs oftener in Bantu and colored people than in whites. This case in a Bantu man was due to a sulfonamide.
Ancylostoma caninum are commoner at the coast than inland. The incidence of deficiency diseases follows the seasons, and pellagra is commonest before the harvest.

\section{Nutrition}

In South Africa, as in the rest of Africa, malnutrition, especially protein deficiency, is a major problem not only as a cause of deficiency diseases as such but also by predisposing to many other diseases of the skin and other organs. Malnutrition is a factor in the pyodermas, in tropical ecthymatous ulcer, and possibly even, as suggested by Vanbreuseghem, ${ }^{3}$ in the dermatophytoses.

Malnutrition lies behind the liver diseases so common in the Bantu, and hepatic insufficiency probably explains their symptomatic porphyria and may, by causing estrinization, ${ }^{4}$ explain the mildness of their acne. The rarity of xanthomatous eruptions, too, may be due, in part at least, to dietetic factors.

All the manifestations of malnutrition are encountered. Kwashiorkor (Fig. 2) is common in children, and all the syndromes of

Incidence of Common Skin Diseases

\begin{tabular}{|c|c|c|c|c|c|}
\hline Rank & Pretoria White, \% & Pretoria Bantu, \% & Lagos Negro, \% & Lagos White, \% & London White, \% \\
\hline 1 & Eczemas, 28 & Eczemas, 27 & Tinea, 32.6 & Tinea, 22.4 & Eczema, 36.0 \\
\hline 2 & Acne vulgaris, 8.0 & Impetigo, 9.4 & Pyoderma, 15.6 & Pyoderma, 20 & $\begin{array}{l}\text { Seborrheic derma- } \\
\text { titis, } 7.1\end{array}$ \\
\hline 3 & Impetigo, 7.8 & Acne, 9.15 & Scabies, 11.1 & Eczema, 14.1 & Pyoderma, 6.0 \\
\hline 4 & $\begin{array}{c}\text { Fungous infec- } \\
\text { tions, } 6.9\end{array}$ & Pellagra, 6.3 & Eczema, 6.4 & Pompholyx, 5.4 & Warts, 5.5 \\
\hline 5 & Warts, 5.9 & Syphilis, 4.35 & Malnutrition, 5.7 & Seborrheic dermatitis, 5.1 & Acne, 5.0 \\
\hline 6 & Rodent ulcer, 4.5 & Pyodermas, 3.1 & Onchodermatitis, 1.8 & Warts, 4.0 & Psoriasis, 4.8 \\
\hline 7 & Psoriasis, 3.2 & Fevers, 3.2 & Warts, 1.8 & Acne, 3.1 & Tinea, 3 \\
\hline 8 & $\begin{array}{l}\text { (a) Senile and so- } \\
\text { lar keratoses, } 2.1 \\
\text { (b) Seborrheic } \\
\text { warts, } 1.0\end{array}$ & $\begin{array}{l}\text { Warts, } 2.45 \\
\text { Plantar warts or } \\
\text { corns, } 1.25\end{array}$ & Sycosis cruris, 1.4 & Urticaria, 2.6 & $\begin{array}{l}\text { Neurodermatitis, } \\
2.8\end{array}$ \\
\hline 9 & Urticaria, 2.3 & Scabies, $2.4+1.5(?)$ & Pruritus, 1.4 & Psoriasis, 2.5 & Urticaria, 2.0 \\
\hline 10 & Scabies, 2.5 & $\begin{array}{l}\text { Pityriasis versicolor, } \\
2.4\end{array}$ & Acne, 1.3 & Prickly heat, 2.5 & Alopecia areata, 1.8 \\
\hline 11 & $\begin{array}{l}\text { Sandworm, (larva } \\
\text { migrans) } 2.4\end{array}$ & Pityriasis rosea, 2.4 & Urticaria, 1.3 & Larva migrans, 2.1 & \\
\hline 12 & Pyodermas, 1.6 & $\begin{array}{l}\text { Erythema multi- } \\
\text { forme, } 2.1\end{array}$ & Vitiligo, 1.1 & & \\
\hline 13 & Pityriasis rosea, 1.0 & Lichen urticatus, 2.05 & Pityriasis rosea, 1.1 & & \\
\hline 14 & Light eruptions, 1.0 & Fungous infections, 1.85 & Lichen planus, 1.0 & & \\
\hline 15 & Varicose ulcer, 1.2 & $\begin{array}{l}\text { Toxicodermas (in- } \\
\text { cluding fixed erup- } \\
\text { tions), } 1.75\end{array}$ & & & \\
\hline 16 & Lichen urticatus, 1.2 & Urticaria, 1.7 & & & \\
\hline 17 & $\begin{array}{l}\text { Furuncle, car- } \\
\text { buncle, } 1.1\end{array}$ & $\begin{array}{l}\text { Furuncle, carbuncle, } \\
1.6\end{array}$ & & & \\
\hline 18 & Moles, 1.1 & Psoriasis, 1.45 & & & \\
\hline
\end{tabular}



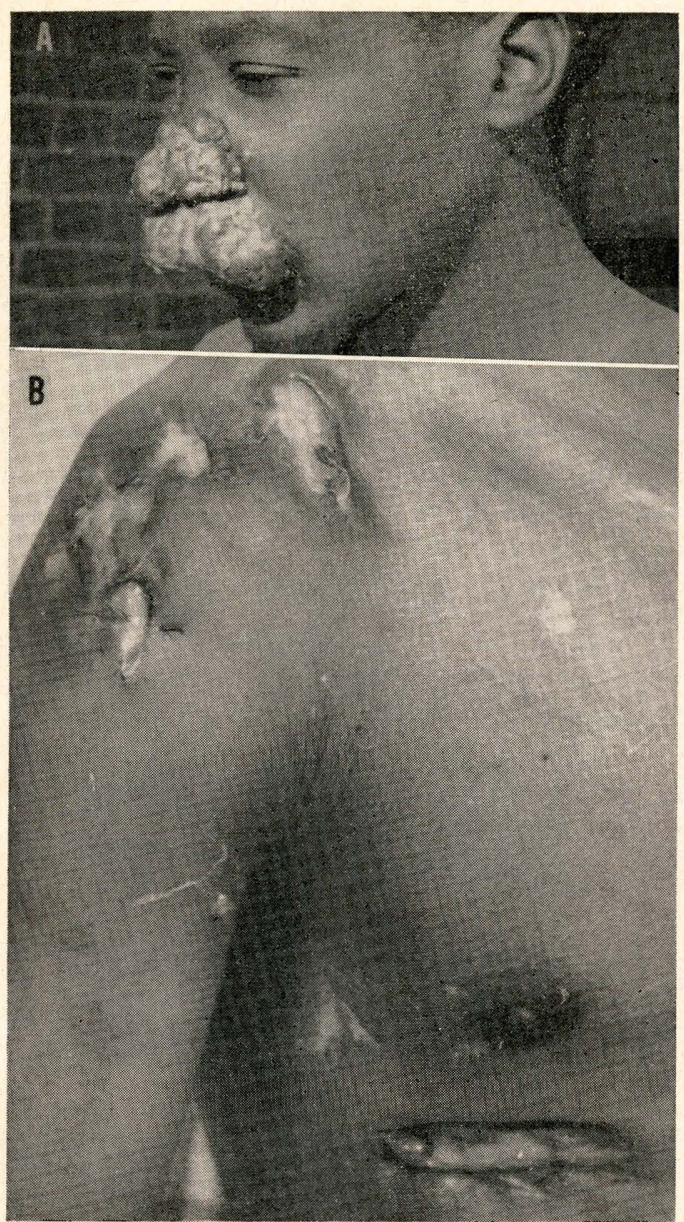

Fig. 5.- $A$ and $B$, lupus vulgaris and scrofuloderma are common manifestations of cutaneous tuberculosis in the Bantu.

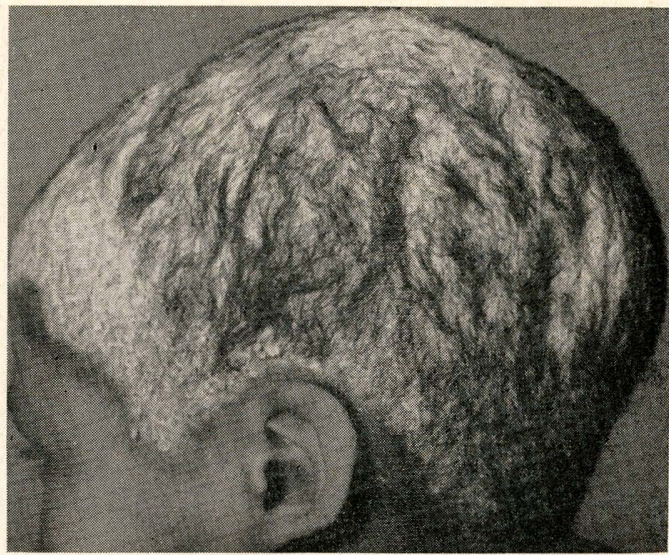

Fig. 6.-Favus is endemic in Bechuanaland, but elsewhere it is rare. This case was cured with griseofulvin $1 \mathrm{gm}$. daily for 25 days.

protein and vitamin deficiencies occur in adults. Maize is the staple diet of the Bantu, and pellagra (Fig. 3) is the commonest clearcut syndrome that one sees.

\section{Migration}

Although there is a large urban Bantu population, a high percentage of Bantu men are migrant workers in industry who leave their wives on the farm and return home for long holidays between spells of work. The gold mines alone attract 400,000 men each year from all over South Africa and as far afield as Central Africa. In these migrant workers one encounters diseases such as yaws, jig-

Fig. 7. $-A$ and $B$, lipoid proteinosis is relatively common in South Africa.
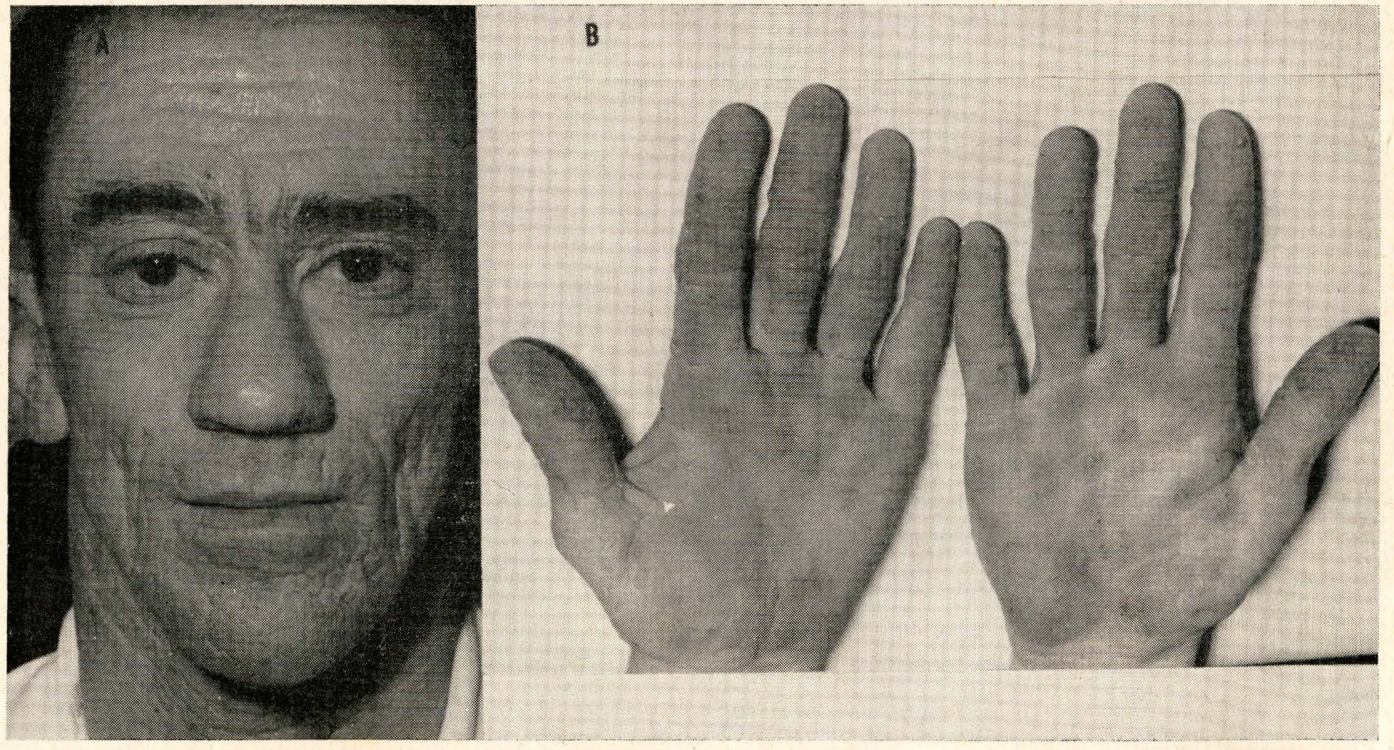

Vol. 87, April, 1963 


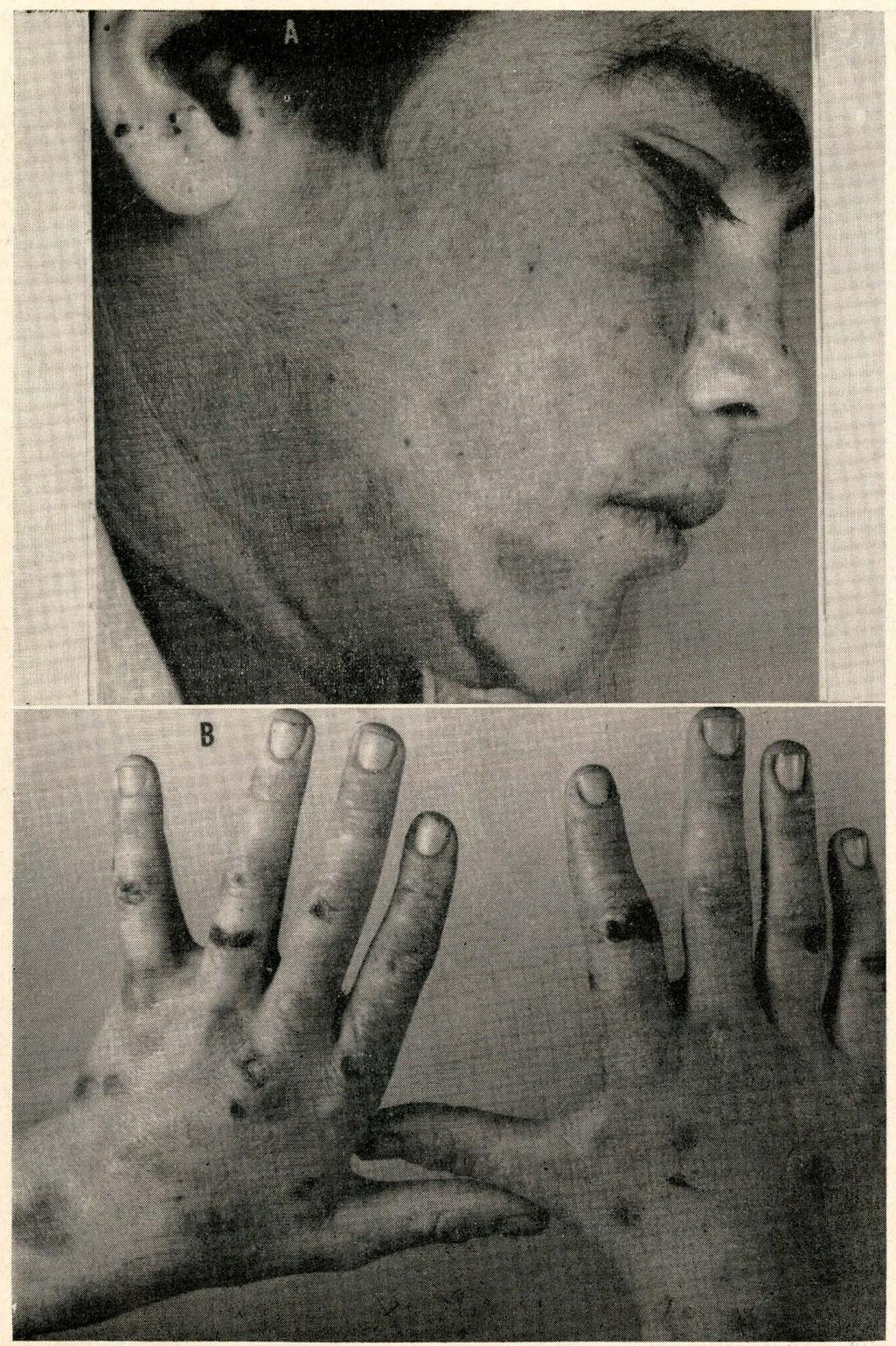

Fig. 8.- $A$ and $B$, a familial hepatic porphyria (porphyria variegata) is common in white South Africans of Afrikaner stock. The cardinal cutaneous signs, shown here, are bullous eruptions and scars on the exposed skin, hyperpigmentation, and hypertrichosis. Attacks of acute prophyria may be provoked by the use of drugs such as sulfonamides or barbiturates.

gers, and onchocerciasis which are foreign to South Africa.

\section{Way of Life and Occupation}

The way of life and hygienic state influence many diseases. The main dermatoses of those who live in dirt and misery are scabies, pyodermas, mycoses, treponematoses, and leprosy.

The traditionally clad Bantu may be dressed for comfort, but his naked state makes him more liable to superficial injury and contagion. Athlete's foot is rare in the unshod, but trauma to the bare foot is a reason why this is a site of election for malignant melanoma in the Bantu.

Most of the occupational dermatoses seen elsewhere occur in Africa. The incidence of industrial dermatitis is lower in the Bantu than in whites.

\section{Medication}

Witch doctors still flourish, and their remedies occasionally cause dermatoses and have been suspected of causing onyalai, an acute thrombocytopenia characterized by hemor- 


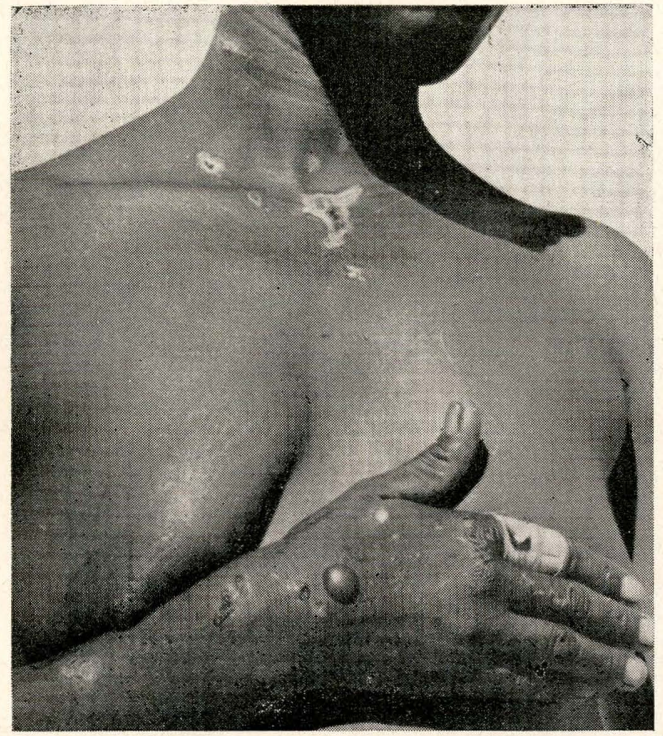

Fig. 9.- Porphyria cutanea tarda in the Bantu is of the acquired hepatic variety.

rhagic bullae on the buccal mucosa and sometimes the skin, and by hemorrhage from the mouth and nose and into the bowels and urogenital tract.

The Bantu are greatly given to purgatives. Phenolphthalein is the favorite; it often causes fixed eruption and sometimes the Stevens-Johnson syndrome (Fig. 4) and toxic epidermal necrolysis. Sulfonamides are another common cause of drug eruptions.

Lack of medication is more important than medication in many country districts where there are too few doctors for the size of population.

\section{The Dermatoses of South Africa}

My remarks on the dermatoses of South Africa are generally applicable to neighboring territories such as South-West Africa, Southern Rhodesia, Mozambique, Basutoland, Swaziland, and Bechuanaland. None of the truly tropical diseases is indigenous in South Africa.

The Table shows the incidence of the common skin diseases (those accounting for $1 \%$ or more of cases under review) among white and Bantu patients at Pretoria General Hospital ${ }^{5,6}$ with comparative figures for $\mathrm{Ne}$ groes and whites in tropical Africa at Lagos, Nigeria, ${ }^{7}$ and Europeans in London. ${ }^{8}$

It will be noted that the disease spectrum of white South Africans resembles that of London far more than that of Europeans in Lagos.

The incidence of eczema in the Bantu in Pretoria is very much higher than it is in country people and suggests that the urban Bantu is developing the same pattern of eczema as the urban white. This phenomenon has been noted elsewhere. ${ }^{9}$

Let us now make a brief systematic survey of the dermatoses. Apart from some racial variation in incidence the eczemas and eczematides present few special features. Pity-

Fig. 10.-Elastolysis (cutis laxa) following an erythema-multiforme-like eruption in a colored boy aged 18 months.

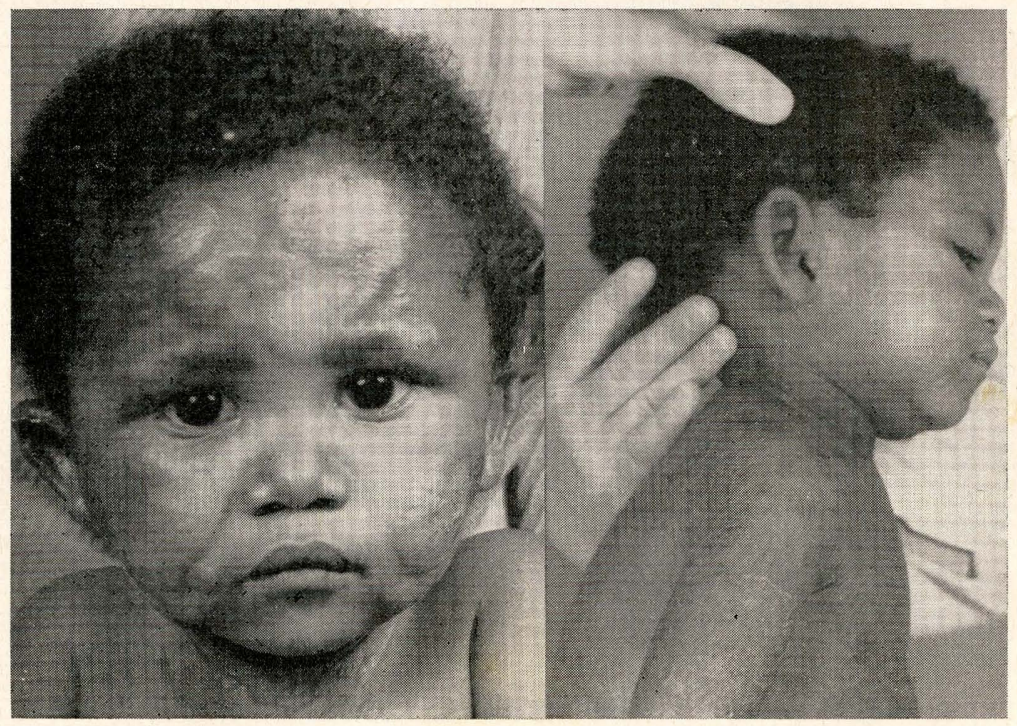

Vol. 87, April, 1963 


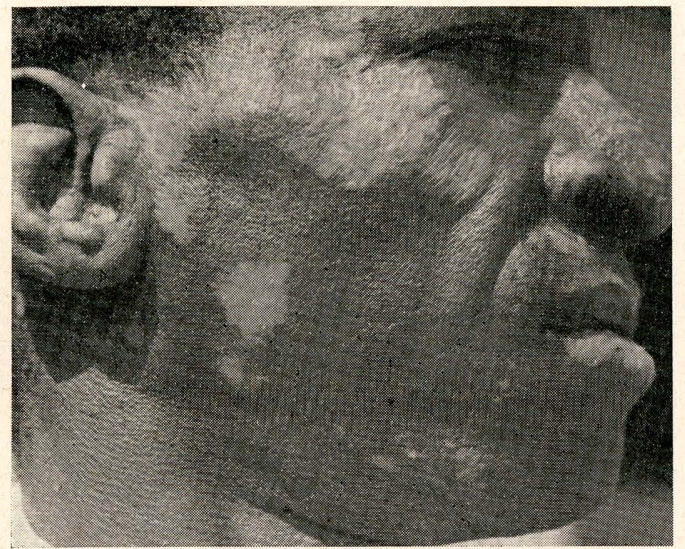

Fig. 11.-Chronic discoid lupus erythematosus is not uncommon in the Bantu.

riasis alba is very common in the Bantu in whom atopic eczema is rare; this contradicts suggestions that the two conditions are related. Varicose eczema and ulcer are rare in the Bantu.
Most of the bacterial skin diseases are commoner in the Bantu and colored people than in whites. Ecthyma of the legs (veld sore) is common, but true tropical ecthymatous ulcer is rare except in Natal. The Bantu often develop Bockhart's impetigo of the shins; this phenomenon has been noted in Nigeria by Clarke ${ }^{11}$ who calls it dermatitis cruris pustulosa et atrophicans and believes it to be a disease entity. Rhinoscleroma and donovanosis are rare, but chancroid is common.

All varieties of tuberculosis cutis and tuberculides are found especially among the Bantu and colored people; lupus vulgaris (which is very rare in whites born in South Africa) and scrofuloderma predominate (Fig. 5).

In 1958 it was estimated that there were 16,000 lepers in South Africa. Most cases

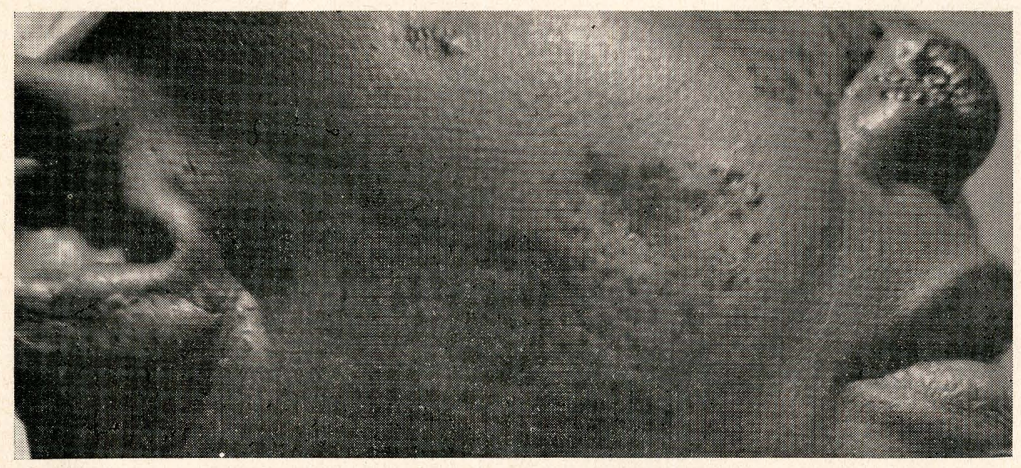

Fig. 12.-Sarcoidosis (morbus Besnier-Boeck -Schaumann) is rare in all races in South Africa. This Bantu woman had lesions of skin and bones.

Urticaria shows no racial preference, but erythema multiforme and the Stevens-Johnson syndrome are commoner in the Bantu and colored people than in whites; most cases are caused by drugs. Erythema nodosum, seen in all races, is less often due to tuberculosis than is the case in Europe.

Dermatitis artefacta and pruritus ani et vulvae are rare in the Bantu, but lichenified eczema of the penis and scrotum is common. The rarity of pruritus ani in Moslems is ascribed to their gentle methods of cleansing, but this cannot explain the immunity of the Bantu whose methods of anal hygiene vary from total neglect to the use of materials more diverse and barbarous than those in Gargantua's list. ${ }^{10}$

61 Marshal occur in the Bantu in the northern half of the country.

Venereal syphilis is the only important treponematosis. Extragenital chancre is rare

Fig. 13.-Chronic solar cheilitis is common in white farmers and fishermen, but is rare in darkly pigmented races. This case in a colored fisherman was treated by excision and plastic repair.

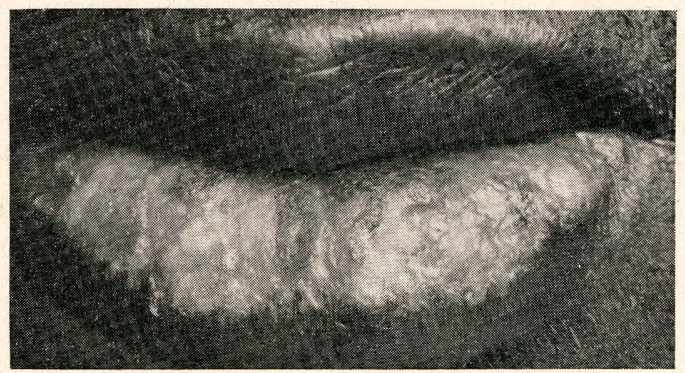




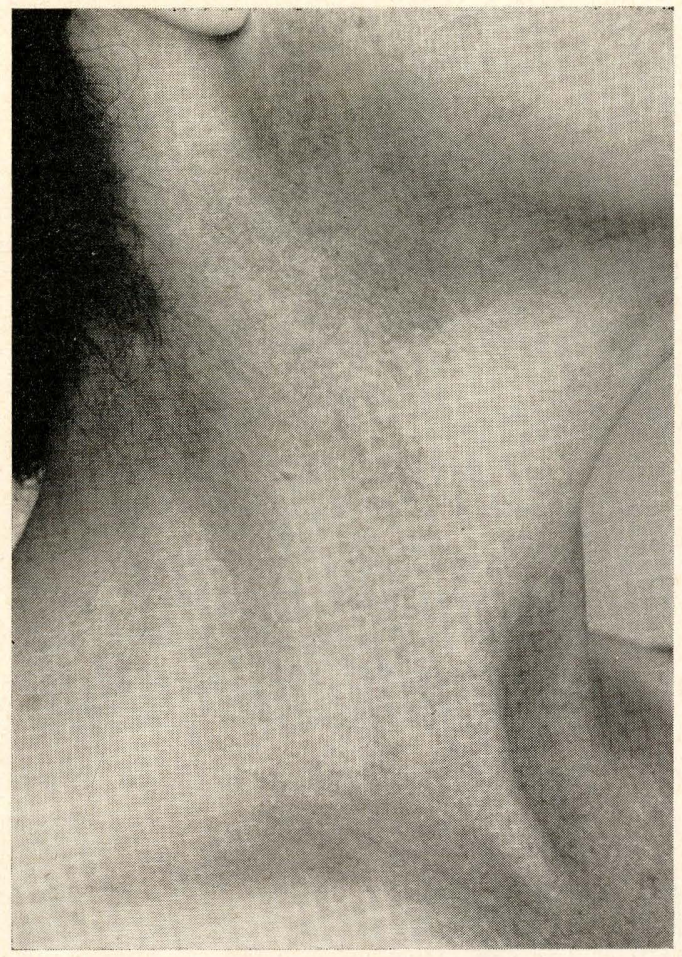

Fig. 14.-Poikiloderma of Civatte is common in white women after 40 . Note how the area shaded by the chin is spared.

in the Bantu whose sexual habits are unimaginative. Yaws is sometimes seen in Bantu immigrants from tropical Africa, and foci of endemic syphilis exist in small communities in Bechuanaland and Rhodesia.

All the virus diseases with the exception of orf are encountered.

Most of the superficial (Fig. 6) and deep mycoses occur ${ }^{12,13}$; notable exceptions are coccidioidomycosis and the North and South American blastomycoses. Ringworm infections are common in all races. In the Transvaal, Microsporum canis is oftenest cultured; in the vicinity of Cape Town, Trichophyton violaceum. Microsporum audouini and Trichophyton rubrum infections are very rare.

Scabies and papular urticaria from fleas are the commonest parasitoses. Cutaneous myiasis due to larvae of Cordylobia anthropophaga (tumbu fly) is seen in the warm northeastern sector. Larva migrans is commonest on the Natal coast where the races are equally afflicted; inland in the Transvaal and Orange Free State white children are quite frequently infested, but the Bantu very rarely. Cutaneous schistosomiasis is sometimes seen; girls are oftenest affected.

Among the metabolic diseases lipoid proteinosis (Fig. 7) and porphyria deserve special mention. Over 30 cases of lipoid proteinosis have been found in South Africa ${ }^{14}$; most are of German or Dutch ancestry.

Rare cases of erythropoietic porphyria have been seen, but South Africa is noted for its high incidence of hepatic porphyria. A familial hepatic porphyria (porphyria variegata) is common in whites of Dutch descent $^{15}$ (Fig. 8). The symptomatic porphyria cutanea tarda of the Bantu is acquired and follows liver damage induced by malnutrition and the abuse of spirits ${ }^{16}$ (Fig. 9). It is comparable to the porphyria caused by hexachlorobenzene fungicides recently described in Turkey. ${ }^{17}$

All the diseases of collagen, elastic tissue, ${ }^{18}$ and fat have been encountered (Fig. 10). Dermatomyositis is relatively common in the Bantu, but it has not yet been found in association with cancer. Chronic discoid lupus erythematosus is by no means uncommon in the Bantu and colored people (Fig. 11).

Most of the vascular diseases and allergides and all the vesicular and bullous diseases occur in all races.

The incidence of the reticuloendothelioses and leukoses is generally lower in the Bantu than in the white, but Kaposi's sarcoma is much commoner in the Bantu, and multiple myelomatosis seems to have no racial preference. Sarcoidosis is rare in all races (Fig. 12).

Basal-cell epithelioma, the commonest malignant tumor of whites, is rare in the Bantu. ${ }^{19}$ Squamous carcinoma usually arises on exposed skin in whites; in the Bantu it oftenest begins in old scars (burns, chronic ulcers) on the lower limbs. Malignant melanoma is commoner in whites than in the Bantu; however, this tumor accounts for $30 \%$ of all skin tumors in the latter, with the foot as site of election. 
All the photosensitivity diseases are common in whites. Farmers and fishermen provide the highest percentage of solar keratoses, cheilitis and leukoplakia, and cancers of the skin and lower lip (Fig. 13). Poikiloderma of Civatte (Fig. 14) is very common in women over 40 , but I have never seen a true melanosis of Riehl such as one saw in France during and just after the last war.

Bantu and colored people often seek attention for diseases causing reactions of hyper- or depigmentation which are striking on the dark skin. Vitiligo is common in all races.

\section{Postscript}

I would like to remind readers that, under the auspices of Stellenbosch University and the South African Council for Scientific and Industrial Research, I am conducting an inquiry into the epidemiology of skin diseases in Africa as a whole. I hope that this first superficial survey of a small part of the problem may stimulate others to supply material.

James Marshall, M.D., Simonsview, Sorrento Road, St. James, Cape Province, South Africa.

\section{REFERENCES}

1. Seligman, C. G. : Races of Africa, Ed. 3, London, Oxford University Press, 1957.

2. Sillery, A.: Africa : A Social Geography, London, Gerald Duckworth and Co., Ltd., 1961.

3. Vanbreuseghem, R.: Tinea Capitis in the Belgian Congo and Ruanda Urundi, Trop. Geogr. Med. 10:103, 1958.

4. Davies, J. P. N.: Sex Hormone Upset in Africans, Brit. Med. J. 2:676, 1949.

5. Findlay, G. H., and Scott, F. P.: Skin Disease in the White South African, S. Afr. Med. J. 34: $159,1960$.
6. Schulz, E. J.; Findlay, G. H., and Scott, F. P.: Skin Disease in the Bantu, S. Afr. Med. J. 36: 199, 1962.

7. Clarke, G. H. V.: Skin Disease in a Developing Tropical Country, Brit. J. Derm. 74:123, 1962.

8. Bettley. F. R., in discussion, in Section of General Practice, Proc. Roy. Soc. Med. 45:492, 1952.

9. Davis, L. R.; Marten, R. H., and Sarkany, I.: Atopic Eczema in European and Negro West Indian Infants in London, Brit. J. Derm. $73: 410$, 1961.

10. Rabelais, F.: La Vie trèshorrifique du grand gargantua, Livre Premier, Chap. 13, 1535 (from Les Cinq Livres de F. Rabelais, Paris, E. Flammarion, 1929).

11. Clarke, G. H. V.: Skin Diseases in the African, London, H. K. Lewis \& Co., Ltd., 1959, Chap. 5.

12. Lurie, H. I.: Fungal Diseases in South Africa, S. Afr. Med. J. 29:186, 1955.

13. Sporotrichosis Infection on Mines of the Witwatersrand: A Symposium, Johannesburg, The Transvaal Chamber of Mines, 1947.

14. Scott, F. P., and Findlay, G. H.: Hyalinosis Cutis et Mucosae (Lipoid Proteinosis), S. Afr. Med. J. $35: 189,1960$.

15. Dean, G., and Barnes, H. D.: The Inheritance of Porphyria, Brit. Med. J. 2:89, 1955.

16. Lamont, N. M.; Hathorn, M., and Joubert, S. M.: Porphyria in the African, Quart. J. Med. $30: 373,1961$.

17. Çam, C.: Porphyries cutanées toxiques et acquises causées per l'hexachlorolbenzène, Bull. Soc. Med. Hop. Paris 76:1305, 1960.

18. Marshall, J.; Vogelpoel, L., and Weber, H. W.: Primary Elastolysis: Report of a Case of Cutis Laxa with Emphysema and a Discussion of Some Syndromes Characterized by Elastolysis, S. Afr. Med. J. $34: 721,1960$.

19. Oettlé, A. G.: Racial Differences in Cancer in South Africa, South African Biological Society, Pamphlet No. 17, 1955. 